\title{
Opiates: benefits and overuse potential
}

\begin{abstract}
This study reviews opiates (endorphin agonists) in treatment of pain and addiction with specific focus on their addictive potential versus benefits. This review suggests endorphin agonists enjoy mood stabilizing and antidepressant properties and have been helpful in treatment of pain, mood and addictive disorders. The evidence is consistent with the observation that slow release opiate preparations with long elimination life do have significant immunity against overuse. Collectively the evidence suggests longacting preparations of opiates are both effective to treat pain, addiction and some mood disorders and represent low risk for overuse.
\end{abstract}

Volume 2 Issue 3 - 2015

\author{
Alen J Salerian \\ Salerian Center for Neuroscience and Pain, USA
}

Correspondence: Alen J Salerian, Salerian Center for neuroscience and pain, 8409 Carlynn Dr. Bethesda, MD 20817, USA,Tel 301204 9004, Email alensalerian@gmail.com

Received: March 25, 2015 | Published: June 03, 2015

Keywords: opiates, pain, addiction, long-acting - slow-release opiates

\section{Introduction}

Endorphins and endorphin agonists have been used to treat various psychiatric disorders as diverse as addiction, pain, mood disorders and psychosis. Of significance a large number of people with chronic pain greatly depend on opiates. The benefits of opiates for people with addiction i.e. heroine, morphine, prescription pain medications have also been well documented. The emergence of slow-releaselong-acting endorphin agonist preparations has significantly reduced risk of overuse consistent with their unique delivery system that practically eliminates euphoric effects. Concerns about potential risk of overuse have made access to endorphin agonists very burdensome contributing to a hostile clinical environment for many individuals who may benefit from endorphin agonists. This article reviews the evidence of potential benefits versus harm from overuse of opiates.

\section{Methods}

Review of literature. We used search terms addiction, depression, pain, chronic pain, dependence ,opiates, methadone, endorphins, abuse, overuse to search through Medline database and Google scholar for articles published between January 1, 2010 till December $1,2014$.

\section{Results}

Potential benefits and addictive properties of endorphin like substances will be discussed under the following subheadings:

i. History

ii. What can we learn about endorphins and endorphin agonists from animal studies?

iii. Complex evidence of antidepressant and mood altering effects of endorphins and endorphin agonists.

iv. Psycho -biology of addiction and new generation slow-release endorphin agonist preparations.

\section{History}

Since ancient times opiates has been utilized as therapeutic agents. A classic article by Weber et al., ${ }^{1}$ eloquently reports the historical evidence of treatment with opiates going back to the first century. ${ }^{1}$ Table 1 summarizes some of those findings.
Table I Therapeutic benefits of opiates: historical evidence

\begin{tabular}{l}
\hline Therapeutic benefits of opiates: historical evidence \\
\hline Dioscurides ( $\left.\right|^{\text {st }}$ century) \\
Galen ( $2^{\text {nd }}$ century) \\
Paracrlsus ( $16^{\text {th }}$ century) \\
Sydenham $\left(17^{\text {th }}\right.$ century) \\
Engelkens ( $18^{\text {th }}$ and $19^{\text {th }}$ centuries $)$ \\
Kraeplin (20th century) \\
Bodkin, Emrich, Nyhuis Maremmani $\left(\left.2\right|^{\text {st }}\right.$ century) \\
\hline
\end{tabular}

\section{What can we learn about endorphin agonists from animal studies?}

Animal studies have elucidated the crucial influences of endorphin agonists. Although animal and human responses cannot be viewed as identical animal studies are of importance to predict human responses. Below is a synopsis of major observations:

i. Morphine seems to both activate and inhibit dopaminergic activity. 2,3

ii. Opiates acutely dampen dopaminergic activity whereas chronic treatment reverses its inhibitory influence. ${ }^{2,3}$

iii. There are significant differences between the self -administration of heroine versus cocaine. Those self administering heroin maintain grooming behavior, pretesting bodyweight and a good state of general health whereas rats self administering cocaine tend to cease grooming behavior, lose up to $47 \%$ of their pretesting body weight and experience profound deterioration in general health. ${ }^{4}$

iv. The increase in self administration of morphine is not infinite and corresponds to a specific pattern: the animal self administers morphine just the sufficient amount to prevent discomfort associated with withdrawal symptoms. ${ }^{3}$

v. Morphine micro injections into the ventral tech metal area of the midbrain produces dopaminergic activation of the mesolimbic pathway consistent with conditioned place preference and reduction of threshold for intracranial electrical self-mutilation. ${ }^{2}$ 


\section{Complex evidence of antidepressant and mood alte- ring properties of endorphins and endorphin agonists}

i. Since ancient times endorphins like substances have been used for depression. ${ }^{1}$

ii. Postmortem examination of brains of suicide victims shows endorphin depletion. ${ }^{5}$

iii. A group of patients with treatment refractory depression and unresponsive to electroconvulsive treatment had positive response to endorphins. ${ }^{6}$

iv. The predominant influence of endorphin like substances are consistent with the clinical and neuroimaging evidence of classic antidepressant response: dampening of sub cortical metabolism with enhancement of prefrontal cortex function. ${ }^{7}$

v. Stress pain and depression share common pathways with endorphins as the crucial mediating influence.

vi. There is a very high rate of premature death among patients after discontinuities of opiates. ${ }^{8-10}$

vii. Long- acting endorphin agonist (methadone, buprenorphine intramuscular heroin) has been standard treatment for addiction to opiates.

\section{Evidence of significantly diminished overuse potential of long-acting - slow-release opiates}

Addictive properties of various substances reflect a consistent pattern: opiates with short latency and elimination half-life are associated with greater addictive potential. It is also true that the greater and the faster the euphoric affect the higher the likelihood of its addictive potency. And the opposite is true for substances with long latency and half-life elimination. ${ }^{11}$ Addictive potency may be calculated with an algebraic equation of $\mathrm{A}=\mathrm{E} / \mathrm{T}$ Max $. \mathrm{T} 1 / 2$ where $\mathrm{A}$ Represents the addictive potency $\mathrm{E}$ is euphoric potency TMAX is the time to reach peak plasma concentration and $T 1 / 2$ is the plasma elimination half-life.

\section{Discussion}

There seems to be compelling evidence to suggest that endorphin agonists have essential therapeutic benefits for diverse psychiatric disorders. Potential overuse does exist yet may be wise to remember the classic Paracelsus observation: Any chemical substance could become a poison. Toxicity depends on amount consumed and its concentration. Evidence suggests that slow-release long-acting opiate preparations are pharmacologically void of euphoric potency and therefore less likely to be over used. Collectively the evidence suggests long-acting opiates are effective to treat pain, addiction and some mood disorders with low risk of overuse. Short acting opiates do present a risk of overuse hence judicious clinical use with close monitoring are of essence.

\section{Acknowledgements}

None.

\section{Conflict of interest}

The author declares no conflict of interest.

\section{References}

1. Weber MM, Emrich HM. Current and historical concepts of opiate treatment in psychiatric disorders. Int Clin Psychopharmacol. 1988;3(3):255-266.

2. Shippenberg TS, Herz, Spanagel. Neural Substrates mediating motivational effects of opiates. Biological Psychiatry. 1991.

3. Woods JH, France CP, Bertalmio AJ, et al. Opioid abuse liability assessment in rhesus monkeys. In: A Herz, et al. editors. Opioids II, Handbook of Experimental Pharmacology. New York, USA: Springer publisher; 1993. p. 609-632.

4. Bozarth MA, Wise RA. Toxicity is associated with long-term intravenous heroin and cocaine self administration in the rat. JAMA. 1985;254(1):81-83.

5. Gross-Isseroff R, Dillon KA, Israeli M, et al. Regionally selective increases in mu opioid receptor density in the brains of suicide victims. Brain Res. 1990;530(2):312-316.

6. Nyhuis PW, Gastpar M, Scherbaum N. Opiate Treatment in Depression Refractory to Antidepressants and Electroconvulsive Therapy. J Clin Psychopharmacol. 20008;28(5):593-595.

7. Salerian AJ. Sensitive dependence of mental function on prefrontal cortex. J Psychol Clin Psychiatry. 2005;2(1):1-4.

8. Salerian AJ. Cases studies of 17 patients. Journal of case reports and studies. 2015;2(5):1-3.

9. Kakko J, Svanborg KD, Kreek MJ, et al. 1-year retention and social function after buprenorphine-assisted relapse prevention treatment for heroin dependence in Sweden:a randomised, placebo-controlled trial. Lancet. 2003;361(9358):662-668.

10. Grant BF, Stinson FS, Dawson DA, et al. Prevalence and co-occurrence of substance use disorders and independent mood and anxiety disorders: results from the national epidemiologic survey on alcohol and related conditions. Arch Gen Psychiatry. 2004;61(8):807-816.

11. Salerian AJ. Addictive potential:A=E/T(max)xt(1/2). Med Hypotheses. 2010;74(6):1081-1083. 